BUI THI THU HANG

DINH TRAN NGOC HUY

PHAN THUY AN

NGUYEN THI BICH NGOC

HUYNH THI MY DUYEN

\title{
Current situation of Bitcoin management and use: perspectives from the world and recommendations for vietnam
}

Bui Thi Thu Hang, Ph.D., Ho Chi Minh Banking University - Lecturer of Economics Department,

Tay Nguyen University,

Daklak, Vietnam,

ORCID: 0000-0002-6148-2117.

Dinh Tran Ngoc Huy, Ph.D., MBA,

Banking University HCMC, Ho Chi Minh city Vietnam-International

University of Japan, Japan,

ORCID: 0000-0002-2358-0699.

Phan Thuy An, M.Sc.,

Tay Nguyen University, Lecturer of Economics Department,

Daklak, Vietnam,

ORCID: 0000-0001-8289-2652.

Nguyen Thi Bich Ngoc, M.Sc.,

Tay Nguyen University, Lecturer of Economics Department,

Daklak, Vietnam,

ORCID: 0000-0002-5122-7905.

Huynh Thi My Duyen, M.Sc., Lecturer of Economics Department,

Tay Nguyen University,

Daklak, Vietnam,

ORCID: 0000-0001-6337-960X.

\section{Introduction}

The rapid development of the 4.0 industrial revolution has been brought many new scientific achievements, including cryptocurrencies (also known as virtual currencies, digital currencies). Bitcoin, classified as cryptocurrencies, is currently the most well-known and widespread cryptocurrency. Most of cryptocurrencies are recorded as clones or variations of the Bitcoin technology (e.g., Litecoin), build their blockchain as a fork of the Bitcoin blockchain (e.g., Bitcoin cash) or on nearly identical transaction ledgers (Saiedi et al 2020). Since its inception in 2009, Bitcoin has always been the currency with the highest transaction volume, accounting for more than half of the market capitalization of cryptocurrencies (figures 1 and 7), providing much-needed liquidity for the other cryptocurrencies and allowing the secondary market for the cryptocurrency ecosystem to flourish. Until now, although there have been many new virtual currencies born, there is no one that can replace Bitcoin's 
leading position. Bitcoin's decades-long dominating position is proved by the fact that it has been the only cryptocurrency whose value has a causality effects on other cryptocurrencies (Saiedi et al 2020).

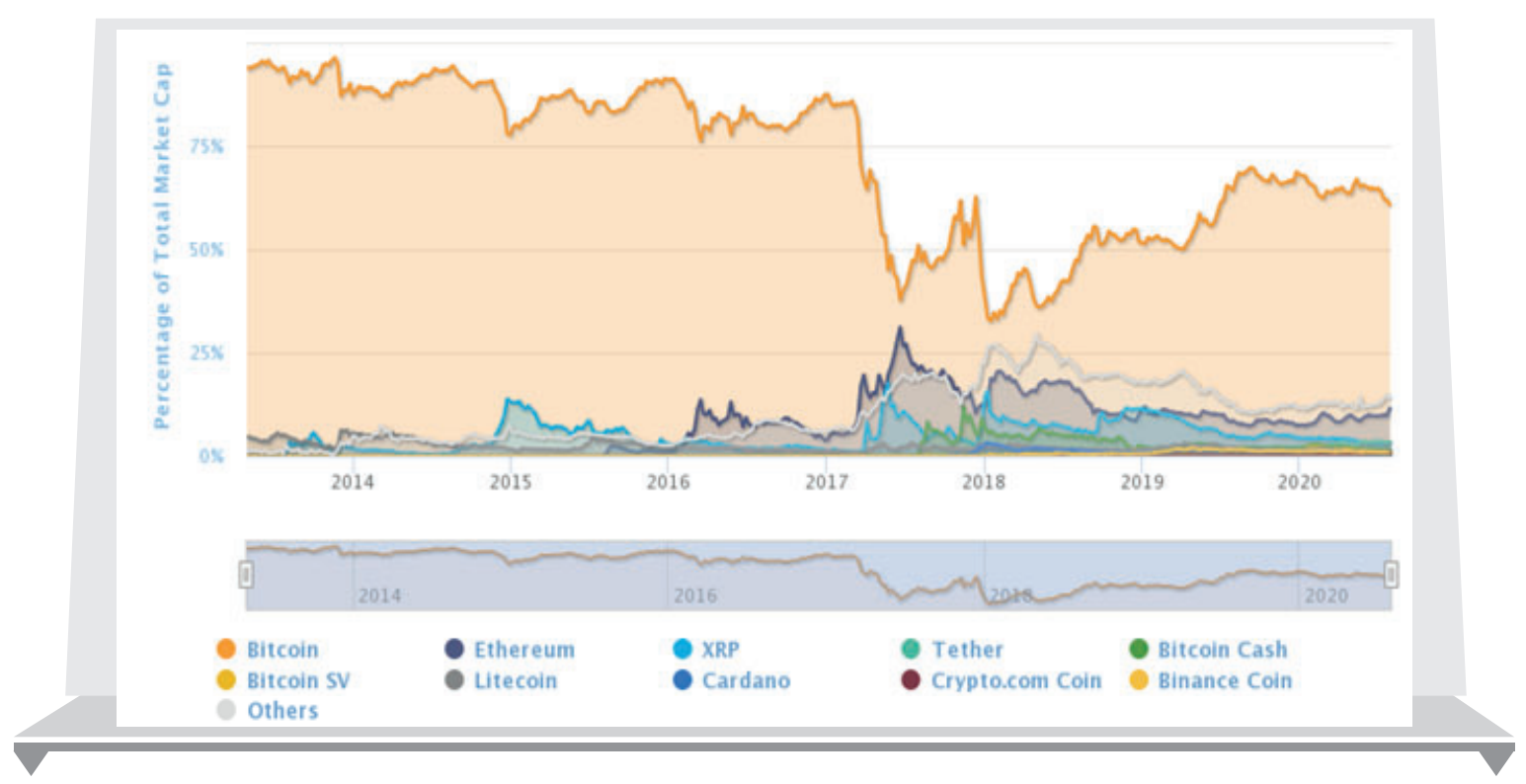

Figure 1. Percentage of Total Market capitalization from 2014 to 2020

Source: coinmarketcap (dated on 1/10/2020)

It can be said that Bitcoin, in particular, and virtual currencies, in general, are high technology products that became assets or goods and are used as investment tools, or as payment methods. However, because the perception of virtual currency and its essence is not really adequate, the approach and management of this kind of currency in each country are different. There are countries that determine the legal use of Bitcoin as a means of payment while others do not recognize even ban entirely (LV Nam 2019). In this context, some subjects have taken advantage of legal loopholes, technological complexity, and public ignorance to mobilize capital illegally (fraud) that damages to organizations and individuals as well as complicates the socio-economic situation.

In Vietnam, although there are a number of works written on the subject of virtual currency, in general, and Bitcoin, in particular, only a few aspects were clarified. For example, LV Nam (2019) focused on clarifying the essence of cryptocurrencies and then suggested recommendations to build a legal

Current situation of Bitcoin management and use: perspectives from the world and recommendations for vietnam 
framework in managing virtual currencies in Vietnam; LTT Nghia and NT Tung (2018) pointed out the challenges of virtual currencies to monetary policy; NB Huyen (2018) had a further step when she provided depth analysis of the advantages and disadvantages of Bitcoin, the situation in managing this currency in the world, and the problems of Bitcoin management and use that are able to raise in Vietnam; and HT Tam, NTK Phuong (2018), besides of presenting detailly the concept, classification, benefits, risks in using virtual currencies, analyzed the current situation of management and use of virtual currencies in the world and proposes recommendations for Vietnam.

Then, we can infer from the result table of ARDL and GARCH model below: the relationship between the lag and price of Bitcoin is almost the same and is significant at the $5 \%$ level. If the price of Bitcoin last week increased by $1 \%$, the effect is an increase in price this week of $0.19 \%$. Moreover, the S\&P 500 seems to have a significant impact on the price of Bitcoin (Oust et al., 218).

Table 1. Result table of ARDL and GARCH model

\begin{tabular}{|c|c|c|c|c|c|c|}
\hline \multirow[b]{2}{*}{ Time Period } & \multicolumn{3}{|c|}{ ARDL } & \multicolumn{3}{|c|}{ GARCH } \\
\hline & (1) & (2) & (3) & (1) & (2) & (3) \\
\hline$\Delta \ln B T C_{t-1}$ & $\begin{array}{c}0.187 \\
(2.05)^{* *}\end{array}$ & $\begin{array}{c}0.226 \\
(2.05)^{* *}\end{array}$ & $\begin{array}{l}0.065 \\
(0.46)\end{array}$ & $\begin{array}{c}0.215 \\
(5.24)^{* * *}\end{array}$ & $\begin{array}{c}0.318 \\
(6.05)^{* * *}\end{array}$ & $\begin{array}{c}0.293 \\
(5.01)^{* * *}\end{array}$ \\
\hline$\Delta \ln S P 500_{t}$ & $\begin{array}{c}1.411 \\
(3.45)^{* * *}\end{array}$ & $\begin{array}{c}1.364 \\
(2.99)^{* * *}\end{array}$ & $\begin{array}{c}1.59 \\
(1.62)\end{array}$ & $\begin{array}{c}0.926 \\
(2.76)^{* * *}\end{array}$ & $\begin{array}{c}0.873 \\
(2.62)^{* * *}\end{array}$ & $\begin{array}{c}0.779 \\
(2.27)^{* *}\end{array}$ \\
\hline$\Delta \ln$ Google $_{t}$ & $\begin{array}{c}0.105 \\
(3.50)^{* * *}\end{array}$ & $\begin{array}{c}0.099 \\
(2.79)^{* * *}\end{array}$ & $\begin{array}{c}0.100 \\
(1.82)^{*}\end{array}$ & $\begin{array}{c}0.033 \\
(2.43)^{* *}\end{array}$ & $\begin{array}{c}0.023 \\
(1.5)\end{array}$ & $\begin{array}{c}0.09 \\
(0.99)\end{array}$ \\
\hline$\Delta \ln$ Google $_{t-1}$ & $\begin{array}{c}0.097 \\
(3.18)^{* * *}\end{array}$ & $\begin{array}{c}0.089 \\
(2.43)^{* *}\end{array}$ & $\begin{array}{l}0.122 \\
(2.82)\end{array}$ & $\begin{array}{c}0.083 \\
(4.66)^{* * *}\end{array}$ & $\begin{array}{c}0.08 \\
(4.68)^{* * *}\end{array}$ & $\begin{array}{c}0.075 \\
(3.91)^{* * *}\end{array}$ \\
\hline$\Delta \ln$ Google $_{t-2}$ & $\begin{array}{c}0.077 \\
(2.01)^{* *}\end{array}$ & $\begin{array}{c}0.084 \\
(1.88)^{*}\end{array}$ & $\begin{array}{l}0.061 \\
(1.06)\end{array}$ & $\begin{array}{c}0.047 \\
(2.63)^{* * *}\end{array}$ & $\begin{array}{c}0.06 \\
(3.35)^{* * *}\end{array}$ & $\begin{array}{c}0.055 \\
(2.84)^{* * *}\end{array}$ \\
\hline ARCH Effect & & & & $\begin{array}{c}0.581 \\
(3.58)^{* * *}\end{array}$ & $\begin{array}{c}0.696 \\
(3.59)^{* * *}\end{array}$ & $\begin{array}{c}0.497 \\
(3.59)^{* * *}\end{array}$ \\
\hline GARCH Effect & & & & $\begin{array}{c}0.324 \\
(2.64)^{* * *}\end{array}$ & $\begin{array}{c}0.269 \\
(2.05)^{* *}\end{array}$ & $\begin{array}{c}0.426 \\
(3.53)^{* * *}\end{array}$ \\
\hline Adjusted $R^{2}$ & 0.29 & 0.23 & 0.50 & & & \\
\hline Observations & 264 & 205 & 56 & 264 & 205 & 56 \\
\hline
\end{tabular}

Note: ${ }^{*} p<0.10,{ }^{* *} p<0.05,{ }^{* * *} p<0.01$. (1) = 2013w1-2018w7, (2) = 2013w1-2016w25, and (3) = 2017w1-2018w7.

Source: own study

Therefore, through qualitative methods to overview the researches, domestic and foreign articles, this article aims to provide a comprehensive view of Bitcoin 
from four aspects, consisting of the concept, the way to trade and exploit, the main characteristics, and the pros and cons. The answer to the question "Is Bitcoin a currency?" also searched by the authors. At the same time, the article goes into depth analysis of Bitcoin management and use in recent years in the world and in Vietnam. On that basis, the authors propose some recommendations to improve the legal framework for the management and use of Bitcoin effectively in Vietnam.

Through the above analysis, the scope of this study will include:

Research issue 1: Whether it is suitable, the role of Bitcoin and cryptocurrencies in a developing economy - the case of Vietnam.

Research issue 2: Policy implications for Vietnam.

\section{Literature review}

\subsection{Previous studies}

Until now, there has not been a consistent concept of Bitcoin. Scholars often describe Bitcoin as follows:

According to Peters et al (2015) Bitcoin is a decentralized currency without the need for intermediaries to conduct electronic transactions or a central bank or single authority to control monetary policy.

According to Weber (2016) Bitcoin is a community-driven, free, open-source project. It provides a platform that allows its users to produce what its proponents call money and to transmit payments anonymously among each other without using established intermediaries.

According to Pavel et al. (2016) Bitcoin is a peer-to-peer payment system created in 2009. It is managed by an open-source software algorithm that uses the global Internet to create and record and verify its transactions.

According to the open encyclopedia (Wikipedia - a), Bitcoin is a cryptocurrency, invented by Satoshi Nakamoto in the form of open-source software since 2009. Bitcoin can be exchanged directly by using Internet-connected devices instead of an intermediary financial institution.

Beside, Bitcoin does not exist in the physical form like other currencies. Besides that, the verification of Bitcoin does not cost anything while the cost of testing gold is very high (NB Huyen 2018). Last but not least, Bitcoin and other cryptocurrencies also failed to operate as a unit of account. Therefore, no many companies and organizations performed accounting and made financial statements use this currency (B Yen 2018, Gerba and Rubio 2020). 
Then, Mizerka et al. (2020) focus on the problem whether the Bitcoin rate of return is mostly driven by capital market situation or major Bitcoin users behaviour. Our results confirmed that there is not, in general, significant relationship between financial market situation (if such relationship does exist, it is found in emerging markets). However, our findings indicate a significant impact of the behaviour of major Bitcoin users on Bitcoin rate of return.

Until now, there are not many researches about Bitcoin and policy implications in Vietnam and identify suitability of Bitcoin and Blockchain in case of Vietnam and emerging markets. This is a research gap we need to explore.

\subsection{The way to trade and "mining" Bitcoin}

Basically, each $\mathrm{BTC}^{1}$ is a computer file stored in the Cryptocurrency Wallet ${ }^{2}$ Application. People can send or receive BTC via their wallets. BTC's transactions are verified by network nodes through cryptography and recorded in a public distributed ledger called a blockchain. This helps users tracking transaction history, proving their ownership (fiahub - a).

The blockchain process is explained as figure 2. BTC is essentially an entry into a public ledger shared by all the participants in a network. Once an owner wants to transfer his bitcoin (or a part thereof) to a third party, in order to avoid double spending, the message is transmitted to all the nodes in the network. It must be verified by certain number of nodes that the BTC is registered against the name of the owner before the transaction is executed and then the ownership is transferred to the new entry through an entry into the same public ledger. It adds as a block to the chain. Hence the name blockchain (Gerba and Rubio 2019).

Users can possess Bitcoin in many ways, including:

- buy Bitcoin with real money through a cryptocurrency exchange;

- accept Bitcoin as payment for goods or services;

- „Mining Coin”: Inspired by the fixed supply of gold, Bitcoin's designers have established a limited stock of 21 million 'coins'.

1 Currency symbol of the Bitcoin cryptocurrency

2 Is a private, public key storage software. In essence, e-wallets, a place to store cryptocurrencies, is used to send, receive money, and track balances. It is like the key to open a blockchain repository, so without it, there would be no way to prove the ownership of electronic assets. If you want to use Bitcoin or any other cryptocurrency, you need a wallet to hold it. Wallets can be used to store multiple coins (coins/tokens) at the same time, but most wallets will only support certain cryptocurrencies (fiahub - c). 


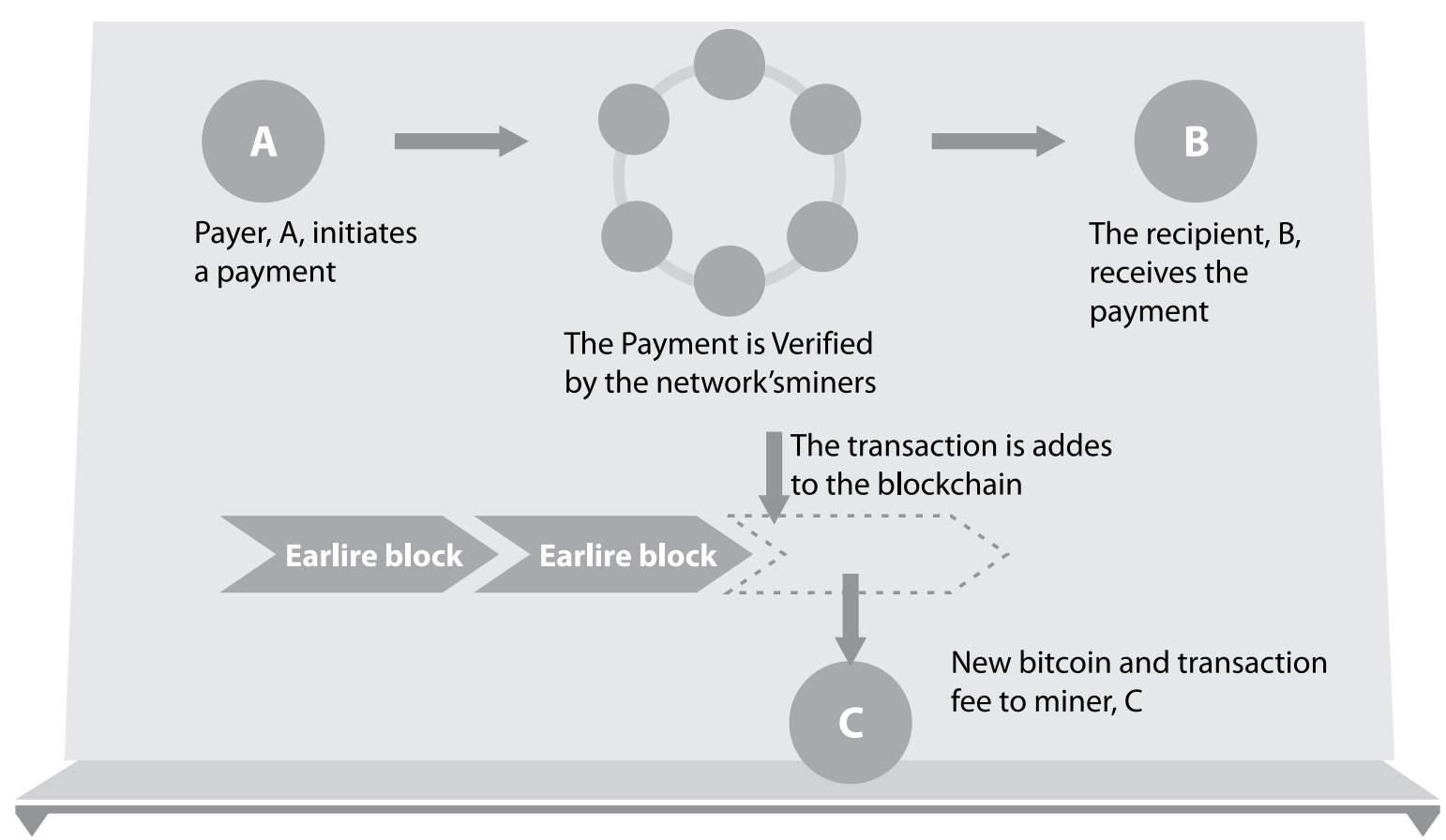

Figure 2. Overview of the blockchain process

Source: Gerba and Rubio 2019

In order to release them for circulation, bitcoins have to be 'mined'. This process, inspired by gold mining, is organised by rewarding nodes for volunteering to transmit a payment between two users. Every 10 minutes the system releases a certain sum of new bitcoins from the vault. Volunteers invest in computer power to participate in the network of nodes in order to compete for obtaining newly released 'coins.' The opportunity to obtain new coins is linked to providing computer power to support the payment system in the network. Whenever a user wants to send bitcoins to another user, the system poses a cryptographic puzzle to the network. Member nodes that have installed the software to solve such puzzles can compete for the fastest solution. Successful solutions print a time stamp on the transaction, which serves as proof that the transaction is based on a unique 'coin' not having been spent by the same user before. The proof is added to a public ledger that contains every transaction in the network, thereby keeping track of all transactions to avoid double spending but without releasing the identity of transaction partners. The updated public ledger is then checked by all other computers in the mining network for correctness of the solution of the underlying puzzle related to each bundle of transactions. If confirmed by the community, the updated version of the public ledger is copied by all network 
members and serves as a decentralized form of keeping account of the history of all transactions in the network. Nodes that deliver successful bids for transaction verification are awarded a certain sum of bitcoins released from the stock-this is the process of 'mining'. The greater the sum of bitcoins already released, the harder the puzzles become to solve (Weber 2016). In short, for the Bitcoin system to work, it is necessary to have confirmations, ledger records, and operations to connect the blocks together. Those are the job of the "miner", and after each block, the successful miner will receive the main reward that is a BTC. This is a way for a new BTC born.

\subsection{The characteristics of Bitcoin}

By analyzing the concepts, ways of trade, and "mine" Bitcoin as above, it can draw on the main characteristics of Bitcoin as follows:

1. Invisibility: Bitcoin is a digital currency that does not exist in any physical shape or form, it can't technically be stored anywhere and has no real value. Instead, it is created in an electronic environment as an online version of cash that can be used to buy products and services.

2. Dispersion: Bitcoin is a decentralized digital currency without a central bank or single administrator to manage or allocate; No one can control and, the transaction history has never lost or been modified.

3. Peer to Peer: making payments by transfer from an entity to another one (figure 2), so there is no need for any intermediaries.

4. No inflation as currency: Bitcoin's total supply is 21 million BTC, meaning that when the market reaches 21 million BTC, it will not be able to create any more Bitcoin. Thus, Bitcoin is immune to inflation compared to the traditional currencies.

5. Global ledger: all transactions are recorded on the global public ledger that can be viewed by anyone.

\subsection{Advantages and disadvantages of Bitcoin}

It can be said that the birth of Bitcoin marked a historic turning point in electronic payment. It has superior advantages compared to other traditional fiat currencies such as:

1. Convenience in transactions: Banks or online payment services (known as transaction intermediaries) usually have a limitation regarding the time, the amount of money transferred, and received during the day, whist Bitcoin is 
not (NB Huyen 2018). In addition, Bitcoin is a currency that can be broken down to almost limitless (the smallest unit of Bitcoin is satoshi), which makes payment accurately and easily (Wikipedia - a)

2. Impossible counterfeit: Bitcoin does not exist in the physical form like other currencies. Besides that, the verification of Bitcoin does not cost anything while the cost of testing gold is very high (NB Huyen 2018).

3. Since its presence in 2009 by group of developers (Nakamoto), Bitcoin has served 62.5 million transactions, approximately and till March 2015, total market value of Bitcoin reached 3.5 b USD (Bohme et al., 2015).

4. High security and very safe: All Bitcoin transactions are public, traceable, and permanently stored in the Bitcoin network, however, the user's identity is completely hidden, users receive Bitcoin on the addresses by random characters (about 30 characters) that are highly confidential. Up to now, there have not been any security issues to lose users' Bitcoin (NB Huyen 2018). On the other hand, Bitcoin is locked in a public encryption system and thus, only the owner can send cryptocurrencies. The strong encryption and the magic of large numbers of characters make Bitcoin impossibly breakable. In addition, after confirmation, transactions are irreversible, unmodified, or deleted by users. As a result, fraud is very unlikely with Bitcoin transactions (fiahub- a).

5. Low transaction costs: Due to the absence of intermediaries, Bitcoin transaction costs are almost zero (NB Huyen 2018).

6. Being environmentally friendly: Bitcoin does not require using chemicals or printing, so it is safe for the environment. Infrastructure for Bitcoin transaction processing is less expensive than the current financial system (NB Huyen 2018).

7. The fast and global: transactions are employed almost immediately and confirmed in minutes. On the other hand, transactions via Bitcoin are not limited in terms of space because Bitcoin operates in the global network, so users can easily send and receive Bitcoin anywhere in the world as long as there are devices with an internet connection (fiahub - a).

8. No need for a central bank: Bitcoin is a peer-to-peer distributed system, so there is no central server or control point. Bitcoin was created through a process called "mining" money, in which miners competed with each other to find the answer to a puzzle while processing Bitcoin transactions. Any member on the Bitcoin network can be a miner, using the processing power of his computer to verify and record transactions. In essence, the Bitcoin mining process has decentralized the central bank's currency issuance, clearing functions, and replaces the need for a central bank (NB Huyen 2018). 
However, Bitcoin also has some disadvantages:

1. Not easy to use: Bitcoin transactions require devices connected to the Internet. Users, thus, need to have knowledge and understanding of information technology (NB Huyen 2018). The poor and the elderly population, illegal migrants, the homeless, or children are difficult to have access to such electronic payment systems (Salomon et al. 2019).

2. Limiting the scope of payment: in a certain area, a number of users are not many because, first, Bitcoin is not easy to use; second, there have still been many legal obstacles once some countries accept Bitcoin as a currency while others are not; (iii) the majority of people are not yet knowledgeable about cryptocurrencies and they, thus, believe that Bitcoin is unreliable.

3. A very strong level of volatility: most fluctuations in the world affect the cryptocurrency and make Bitcoin price volatile (NB Huyen 2018). Bitcoin's volatility makes it impossibly operate as an efficient store of value (B Yen 2018).

4. Being a "fertile land" that attracts the attention of hackers and money laundering criminals: Because of unregulated transactions, virtual money has been targeted and used by many criminal groups as a means of transaction. Hackers can also find and attack Bitcoin exchanges and steal, not to mention money laundering can happen at any time (NB Huyen 2018).

5. Finally, Bitcoin and other cryptocurrencies also failed to operate as a unit of account. Therefore, no many companies and organizations performed accounting and made financial statements use this currency (B Yen 2018, Gerba and Rubio 2020).

\subsection{Is Bitcoin a currency?}

Money plays three main functions in the economy, including store of value, (2) medium of exchange, and a unit of account (standards of value/measure of value). In order to evaluate whether Bitcoin can be considered as money, we will analyze whether Bitcoin can fulfill these three functions.

Is Bitcoin a store of value? When temporarily there is no need to use the currency as a medium of exchange or payment, it is stored for future transaction needs. Money then acts as a store of value or purchasing power over time. When it comes to storage, it is especially important that the currency maintains the same value. Thus, the currency stored must ensure that its value must be stable. In this respect, Bitcoin is difficult to be able to meet because it has large fluctuations in exchange rates compared to traditional currencies (figure 3). Bitcoin transactions first took place in 2009 and the first exchange rate announced by New Liberty 
Standard was 1 USD $=1,309.03$ BTC. Nearly 4 years later, at the beginning of January 2013, the transaction price of 1 BTC was about 13 USD. By the end of November 2013, the price of Bitcoin virtual currency exceeded USD 1,000 for the first time, but by April 2018 it decreased at approximately USD 9,000 / BTC after reaching the highest point in the history of USD 20,000 / BTC on the end of December 2017 (LTT Nghia and NT Tung 2018). In 2019, the Bitcoin price fluctuated sharply, the lowest at $\$ 3,407.20$ on February 7, 2019, and the highest at $\$ 12,429.07$ on July $9,2019$.

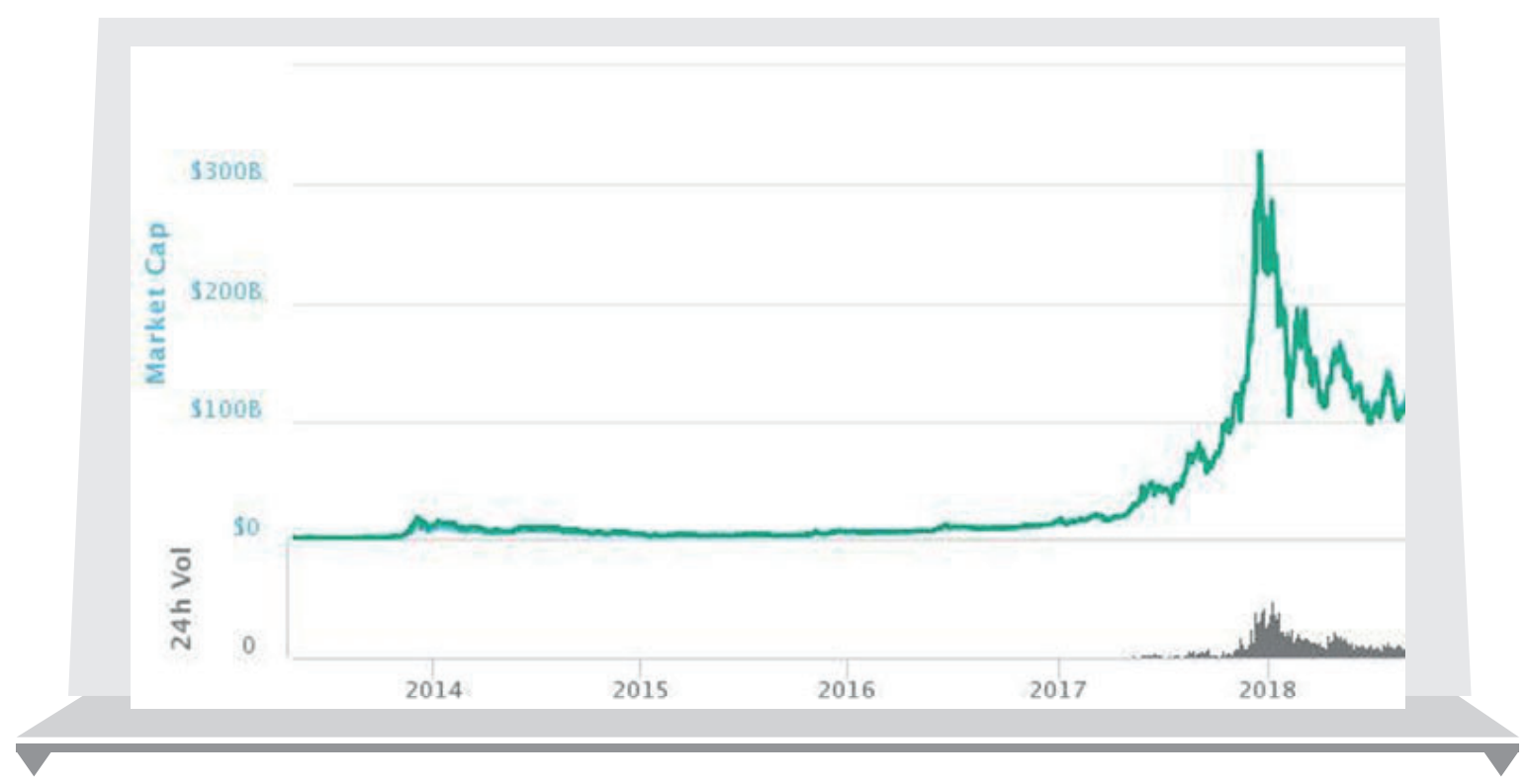

Figure 3. Bitcoin price since 2009 to 2019

Source: Gerba và Rubio 2020

Money is one of the best stores of value because of its liquidity (liquidity ${ }^{3}$ ). Liquidity is essential for any tradable asset including Bitcoin. An asset with high liquidity if it can be sold quickly without a significant reduction in selling price, and often is characterized by a large number of transactions (Wikipedia - b).

3 The concept of liquidity has many facets. One way of defining liquidity is the ability of an asset to be converted to cash on demand (the fastest time and/or the lowest cost). Another view is that liquidity is determined by the bid-ask spread, and an investment with a lower bid-ask spread has higher liquidity. Liquidity thus means that there aren't discounts or premiums attached to an asset during buying or selling, and it is easy to enter and exit the market (Bajpai 2020)

Current situation of Bitcoin management and use: perspectives from the world and recommendations for vietnam 
Figure 4 describes Bitcoin's daily trading volume for the past 5 years. In 2014, Bitcoin's daily trading volume was below \$ 100 million and sometimes it fell below $\$ 10$ million, but by early 2018, that number had risen to over $\$ 20,000$ million. However, Bitcoin also witnessed poor liquidity after the Bitcoin price collapsed when the volume often fell below \$5,000 million per day. Currently, Bitcoin's daily trading volume regularly exceeds \$20,000 million (Bajpai 2020). Figure 5 also shows the number of Bitcoin transactions per month increasing significantly over time from 2009 to 2017.

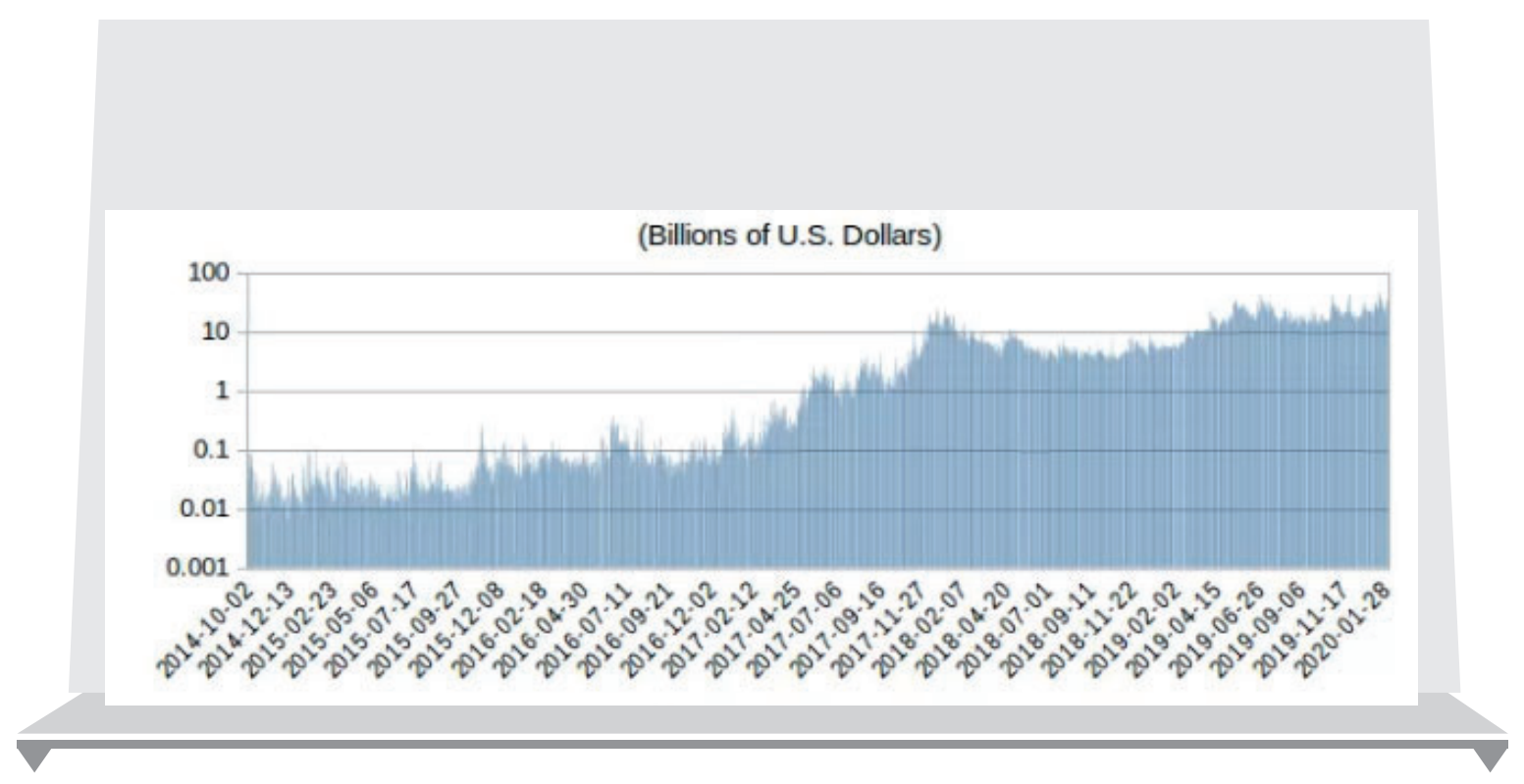

Figure 4. Bicoin daily volume

Source: coinmarketcap $(1 / 10 / 2020)$

When considering digital currencies as a store of value, safety is a concerning issue. Because the digital currency does not exist in a physical form, it cannot, literally, be concealed. Instead, it is held in computer accounts known as digital wallets. The security measures for digital currencies are undertaken by signing a pack of insurance, however, users must pay these costs (Gerba and Rubio 2020).

Is Bitcoin a medium of exchange? Currency serves as a medium of exchange, which means that money acts as an intermediary between the buyer and the seller. In the world, the number of retailers accepting Bitcoin as a means of payment is increasing. However, in fact, retailers' acceptance of this currency 
does not automatically mean that it will be used. In order to know whether Bitcoin is really a medium of exchange or not, it is important to track the number of transactions made with this currency over time (Gerba and Rubio 2020). Figure 5 shows that this number has increased greatly over time.

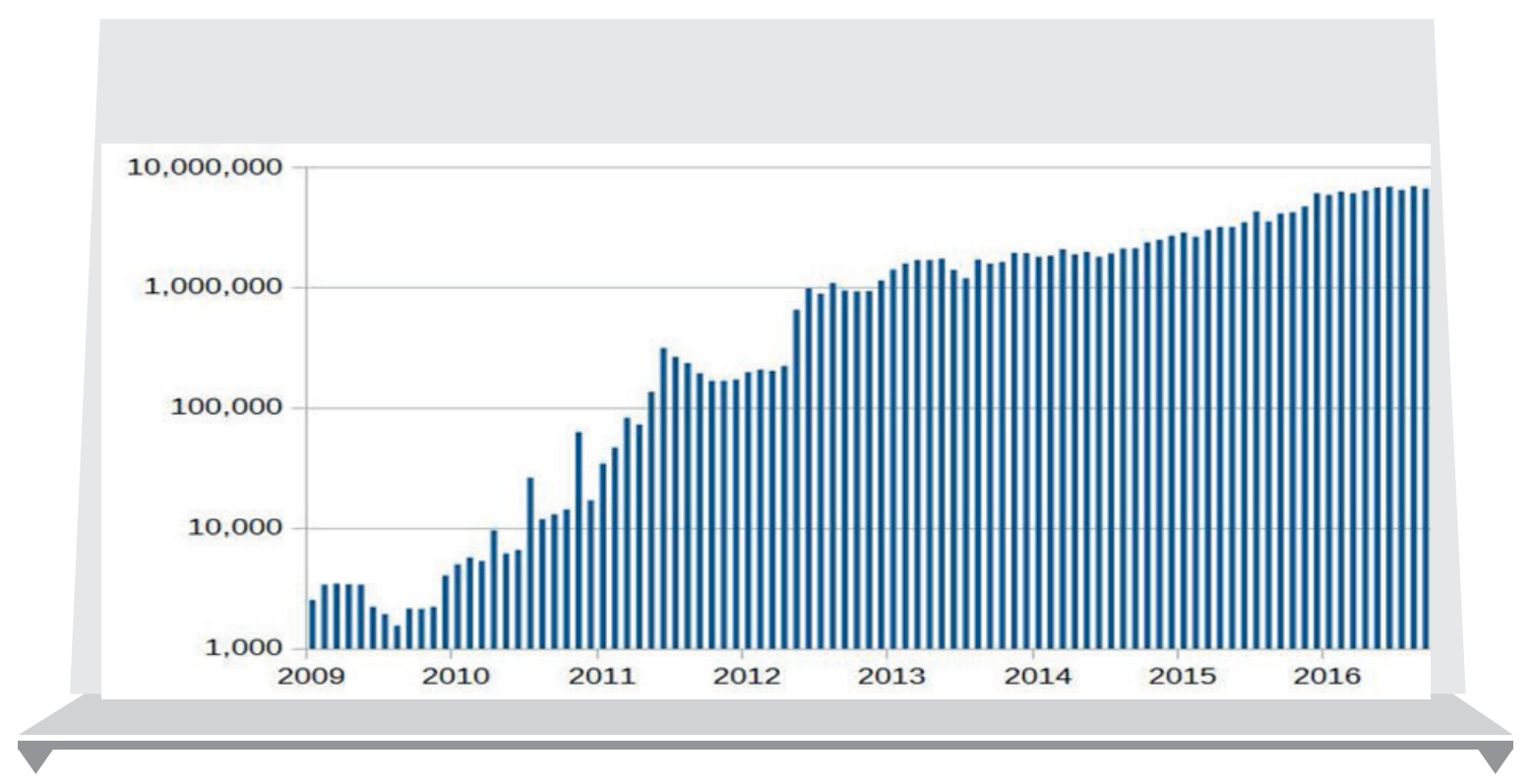

Figure 5. Number of bitcoin transactions per month since 2009 to 2017

Source: Gerba và Rubio 2020

Another difficulty for Bitcoin to be a medium of exchange is its supply. Consumers can only have access to Bitcoin from online exchanges or dealers. Moreover, it cannot bypass the requirement of possessing it before purchasing goods and services from a merchant. To date, there are no credit cards or consumer loans denominated in Bitcoin (Gerba and Rubio 2020).

Is Bitcoin a unit of account? Until now, there has been little evidence of BTC used as a unit of account. The extreme volatility of the BTC's exchange rate is also a problem to consider whether BTC serves as a unit of account or not. For example, the value of a Bitcoin, compared to other currencies changes dramatically on a day-to-day basis. Retailers have to recalculate prices frequently and this can be costly and cause confusion. The uncertain market value of digital currencies would make it very difficult to use as a valid reference point for setting consumer prices (Gerba and Rubio 2020). Table 1 shows the price of 1 BTC in daily dollars and transaction volume. 
Table 1. Bitcoin-USD Price and Volume of Transactions

\begin{tabular}{c|c|c|c|c}
\hline Date & Open & High & Low & Volume \\
\hline $23 / 11 / 2019$ & $7,298.17$ & $7,298.172$ & $7,207.51$ & $34,342,412,288$ \\
\hline $22 / 11 / 2019$ & $7,643.57$ & $7,697.38$ & $6,936.71$ & $34,242,315,784$ \\
\hline $21 / 11 / 2019$ & $8,023.64$ & $8,110.10$ & $7,597.38$ & $22,514,243,371$ \\
\hline $20 / 11 / 2019$ & $8,203.61$ & $8,237.24$ & $8,010.51$ & $20,764,300,436$ \\
\hline $19 / 11 / 2019$ & $8,305.13$ & $8,408.52$ & $8,099.96$ & $21,083,613,815$ \\
\hline
\end{tabular}

Source: Gerba và Rubio 2020

Another problem is that merchants quote prices for most goods in four or more decimal places. Although the aspect, mathematically, does not lead to any problem, it makes consumers disconcerting (Gerba và Rubio 2020). Table 2 provides an example of how cars are priced by bitcoins.

Table 2. Price of cars in Bitcoins and USD

\begin{tabular}{c|c|c|c|c|c}
\hline Crice & $\begin{array}{c}\text { Honda } \\
\text { Accord }\end{array}$ & $\begin{array}{c}\text { Ford } \\
\text { Fusion }\end{array}$ & $\begin{array}{c}\text { Toyota } \\
\text { Corolla }\end{array}$ & $\begin{array}{c}\text { Nissan } \\
\text { Sentra }\end{array}$ & $\begin{array}{c}\text { Chevrolet } \\
\text { Cruze }\end{array}$ \\
\hline Price in Bitcoin & 3.26713809 & 3.06614742 & 2.57129451 & 2.35505627 & 2.35297705 \\
\hline Price in USD & 23,570 & 22,120 & 18,550 & 16,990 & 16,975 \\
\hline
\end{tabular}

Source: Gerba và Rubio 2020

Moreover, it is difficult for Bitcoin, in current form, would be the main form of money for the economic system. Many people are not really familiar with the technology or applications that are not very safe have extreme volatility in exchange rates. On the other hand, digital currencies lack some other features that are associated with money in the economy. For instance, digital currencies cannot be stored as bank deposits; they are not a unit of account for loans and mortgages; or they do not exist in forms of credit cards (Gerba và Rubio 2020).

In short, Bitcoin in particular, digital currencies in general can serves as money for anyone holding computers or internet-enabled devices. However, in fact, this function only happens to a certain extent, and only for a few people. They must always parallel with traditional currency users. In essence, digital currencies 
are an investment being similar to Internet stocks in the late 1990s. Therefore, we conclude that Bitcoin is primarily regarded as a store of value rather than as a medium of exchange. Also, there is very little evidence of digital currencies used as a unit of account. As a result, Bitcoin hardly meets the criteria regarding the function of money. Users can face some risks if they use the kind of currency extensively in the long run.

\section{Method and data}

We use real data from reliable sources such as: coinmarketcap and others.

In this study, we mainly analyze data and generate comments from table of data relating to Bitcoin situation in the world.

Hence we use qualitative analysis with a combination of synthesis, analytical and dialectical materialism method, considering a changing economy in technology era.

\section{Findings on Current situation of Bitcoin management}

\subsection{Current situation of Bitcoin management in some countries in the world}

Virtual currency, especially Bitcoin, a new type of property created by humans, combined with modern technology, has become a social phenomenon legislators and regulators must concern. At the first stage, the virtual currency was a type of asset that was exchanged, purchased, and paid in the transactions of the people who created or related to its circulation. However, currently, this currency has becoming assets, means of payment, investment tools, methods of raising capital, etc,. Therefore, establishing a legal framework of virtual currencies is necessary. However, approaches of countries on virtual currencies do not uniform (LV Nam 2019). According to the statistics of HT Tam and NTK Phuong (2018), Bitcoin and other virtual currencies are not banned in 107 countries out of 251 listed countries. Currently, the approach and recognition of the legal position of Bitcoin in particular, and virtual currencies in general of the countries in the world can be divided into the following levels:

\subsubsection{Accepting Bitcoin}

At this level, Bitcoin is recognized as a means of payment existing in parallel with the national currency and has the policy to regulate transactions (LV 
Nam, 2019). Japan was the first country to fully accept Bitcoin by enacting a law accepting Bitcoin and other virtual currencies as one of the official payment methods. In particular, on 1 April 2017, an amendment (Amendment) to the Payment Services Act of Japan (PSA) and relevant cabinet ordinances came into effect, introducing a regulatory regime for virtual currency businesses. Under the Consumption Tax Act, since July 2017, virtual currency trading is not subject to consumption tax. In September and December 2017, the national tax agency of Japan revealed its position on the taxation status of VCs. In its view, profits derived from VC trading are subject to income tax, categorized in principal as "miscellaneous income." Under the categorization of "miscellaneous income", profits from VC trading are calculated using "aggregate taxation", meaning that profits derived from VCs is aggregated together with other income such as salary or business income and then taxed at a rate of approximately $5 \%$ to $45 \%$ under the graduated tax system (HT Tam and NTK Phuong 2018).

\subsubsection{Adjusting Bitcoin}

Countries tend to adjust Bitcoin are countries have regulations, drafts of Bitcoin. Most of the developed countries in the world belong to this group.

The United States is the country having the most regulations regarding virtual currency, however, there is a differing picture state by state. California issued the Bitcoin Foundation that did not recognize the legality of Bitcoin stopped all commercial transactions relating to the virtual currency. Several states are planning on approving Bitcoin and blockchain technology, while others, such as Arizona, Vermont, and Delaware have adopted bills. The US Securities and Exchange Commission (SEC) issued a Statement warning investor about the level of risks involved in virtual currency investments and claiming that regulations of cryptocurrencies are necessary to stricter. The Commodity Futures Trading Commission (CFTC) became the first US agency to allow cryptocurrencies publicly traded in derivatives markets. The Internal Revenue Service (IRS) issued Notice 2014-21 (March 25, 2014) that stated that Bitcoin is property and not currency for tax purposes. According to the Notice, Bitcoin transactions are taxable by law just like transactions in any other property. Taxpayers transacting in virtual currency may have to report those transactions on their tax returns. Taxpayers receiving Bitcoins as payment for goods or services must include in their gross income the fair market value of the Bitcoins. If bitcoin is held as a capital asset, like stocks, 
bonds, and other types of investment assets, taxpayer must treat them as property for tax purposes. Any gain or loss from the sale or exchange of the asset is taxed as a capital gain or loss. Some people "mine" Bitcoin by using computer resources to validate Bitcoin transactions and maintain the public Bitcoin transaction ledger. According to the IRS, when a taxpayer successfully "mines" Bitcoin and has earnings from that activity whether in the form of Bitcoin or any other form, he or she must include it in his gross income after determining the fair market dollar value of the virtual currency as of the day you received it. If a bitcoin miner is self-employed, his or her gross earnings minus allowable tax deductions are also subject to the self-employment tax. Taxpayers who fail to fulfill their tax obligations on Bitcoin will be penalized according to US law. The US Department of Revenue requires that transactions related to Bitcoin be recorded for tax administration (HT Tam and NTK Phuong 2018).

Almost all members of the European Union have Bitcoin regulations aiming mainly to minimize crimes of money laundering, however, they have not yet legalized the use of Bitcoin as currency (NB Huyen 2018).

A similar trend appears in the Americas from Canada to Argentina. Whereas, in Russia, regulations of Bitcoin have always been the subject of controversy, although the central bank of this country has introduced regulations treating cryptocurrencies as an asset (NB Huyen 2018).

South Korea is also the country with the largest demand for Bitcoin exchange and trading in the world. It is estimated that two million people owned digital currencies in this country. According to Korean Law, reporting more than 20 billion won (about 424.7 billion in VND) have to pay 22 percent and 2.2 percent of corporate and local income taxes out of their revenues (NB Huyen 2018).

\subsubsection{Denial and prohibition of Bitcoin}

Some countries have banned entirely organizations and individuals from trading, buying, selling, using virtual money in general, and Bitcoin, in particular. The countries applying this policy include Iceland, Bolivia, Ecuador, Bangladesh, Kyrgyzstan, Vietnam ... A particular example is Iceland where has the largest Bitcoin mining enterprises in the world, but its residents are not allowed to trade Bitcoin (NB Huyen 2018).

Another example of a country that prohibits circulation of Bitcoin is China. China was used to account for $90 \%$ of the global Bitcoin trading volume, however,

Current situation of Bitcoin management and use: perspectives from the world and recommendations for vietnam 
since Chinese regulatory authorities had imposed a ban on virtual currency transactions, traders have turned to underground markets or ones that have legalized bitcoin trading such as Japan. On September 4, 2017, China banned all companies and individuals from raising capital through Initial Coin Offering (ICO), a cryptocurrency-based fundraising process, and termed it illegal. On February 5, 2018, the People's Bank of China announced that it would block access to all domestic and foreign cryptocurrency exchanges and ICO websites (HT Tam and NTK Phuong 2018).

\subsection{Current situation of Bitcoin management in Vietnam}

In Vietnam, there are no specific regulations regarding payment through virtual currency in general and Bitcoin, in particular. Therefore, to provide an overview for the reader, the authors will conduct an outline of legal documents in relation to virtual currencies and Bitcoin as follows:

First, according to the provisions of the Civil Code (2015), Bitcoin and virtual currencies are not an asset. In particular, Article 105 states that: "(1) Property comprises objects, money, valuable papers and property rights; (2) Property includes immovable property and movable property. Immovable property and movable property may be existing property or off-plan property."

Second, Bitcoin is not a currency and is not a legal means of payment in Vietnam. Clause 6, Article 4 of Decree No. 80/2016/ND-CP regulated that "non-cash payment instruments in payment transactions (hereinafter referred to as payment instruments), including Cheques, payment orders, collection orders, bank cards and other payment instruments as prescribed by the State Bank. "In addition, Clause 7, Article 4 of this Decree stipulates that "illegal payment instruments are payment instruments not included in Clause 6 of this Article. Especially, in Official Letter 5747/NHNN-PC (2017), the State Bank of Vietnam also affirmed that "Virtual money, in general, and Bitcoin, Litecoin, in particular, are not a currency and not a legal means of payment in accordance with Vietnam law. "Issuing, supplying, and using virtual currencies in general and Bitcoin, Litecoin in particular (illegal means of payment) as currency or means of payment is a prohibited act "...The State Bank of Vietnam has also warned that investing in virtual currencies has huge potential risks for investors".

Third, according to the Law on the State Bank of Vietnam No. 46/2010/QH12 and Circular No. 19/2014/TT-NHNN of August 11, 2014, Bitcoin is also not one of the forms of foreign exchange. 
Thus, the issuance, supply, and use of virtual money in general, and Bitcoin in particular in Vietnam as a currency or means of payment is a prohibited act. Behaviors violating the regulations are penalized. For example, under the provisions of Clause 6, Article 2 of Decree No. 96/2014/NĐ-CP penalties for administrative violations against currency, issuing, providing and/or using Illegitimate payment instruments will be applied the fines of VND 150,000,000 - 200,000,00. From January 1, 2018, these acts will also be prosecuted for criminal liability. In case, subjects perform Bitcoin transactions for the purpose of money laundering, they will be sanctioned for administrative violations with a penalty corresponding to the violation as prescribed in Articles, from 39 to 46 in the above Decree. Moreover, According to Point h, Clause 1, Article 206 of Law No. 12/2017/QH14 dated June 20, 2017 on amendments to the Criminal Code No. 100/2015/QH13, issuing, providing, using of illegal payment facilities; forging payment documents or payment facilities; using fake payment documents or payment facilities causes a loss of from VND $100,000,000$ to under VND 300,000,000 for another person shall be liable to a fine of from VND 50,000,000 to VND 300,000,000 or face a penalty of 06 - 36 months' imprisonment. If offense results in property damage of VND 3,000,000,000 or over, the offender shall face a penalty of 12 - 20 years' imprisonment. Also, according to the provisions of Clause 1, Article 324 of the Criminal Code 2015, the act that is considered money laundering will be sentenced to between 1 and 5 years of imprisonment.

\section{Discussion on Current situation of using Bitcoin}

\section{1. Current situation of using Bitcoin in the world}

Cryptocurrencies are being adopted rapidly and broadly. A decade on since their dawn with the invention of Bitcoin, the value of all cryptocurrencies reached $\$ 0.25$ trillion while there are \$ 1.7 trillion and 1.4 trillion euros in circulation (Saiedi et al. 2020). Regarding the kind of cryptocurrencies, while in 2009, there were only a few ones, this number increased to 1,574 in on April 20, 2018 (HT Tam and NTK Phuong 2018), reached to 2,802 on July 28, 2020 (coinmarketcap). The total market capitalization of cryptocurrencies around the world has also increased dramatically, from \$ 1.63 billion on May 1, 2013 to \$ 357.58 billion on April 20, 2018 (coinmarketcap). 


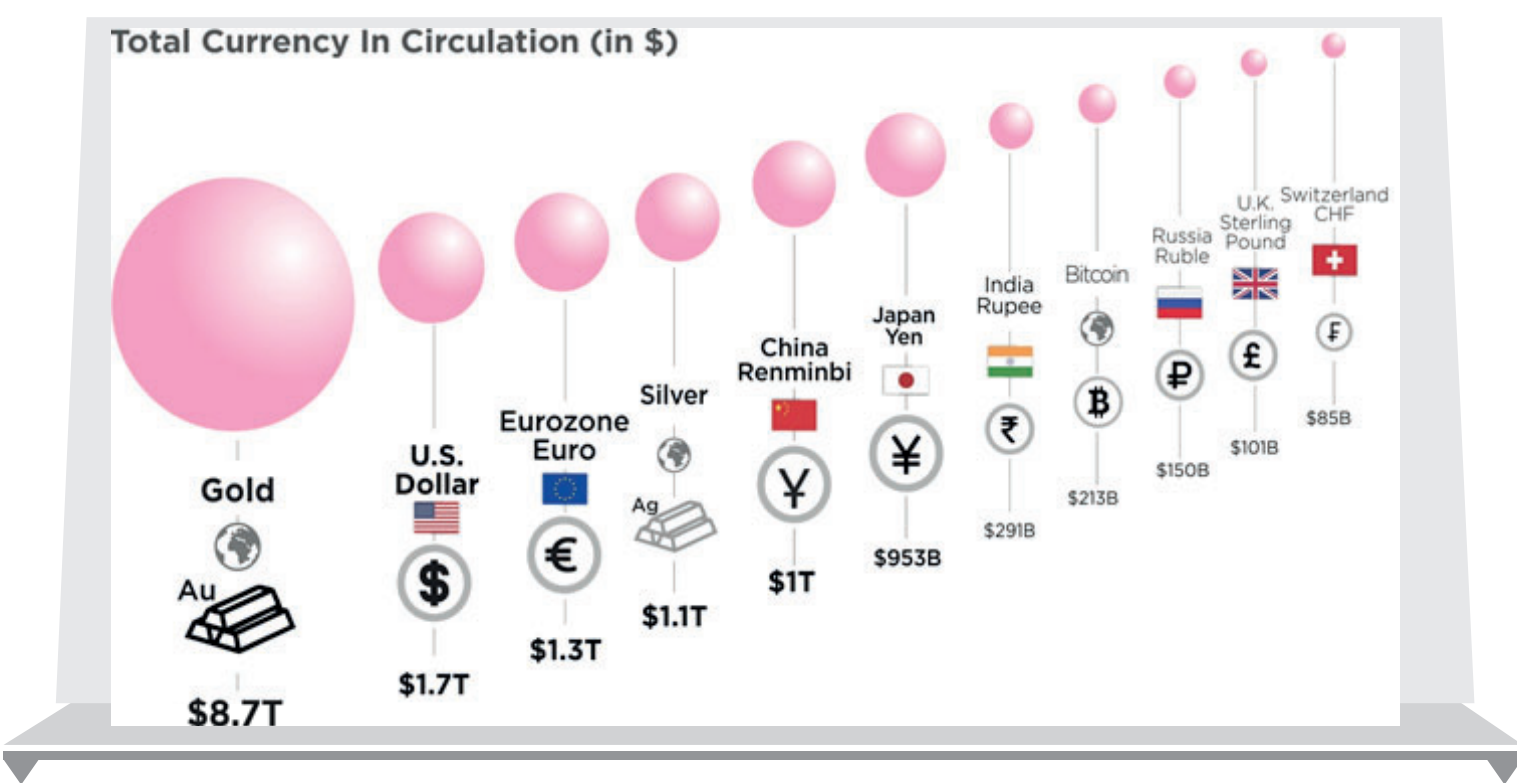

Figure 6. Total currency in circulation (in USD)

Source: https://howmuch.net/articles/how-much-currencies-are-worth (dated on 1/10/2020

As of November 2019, Bitcoin was the sixth most circulated currency in the world, behind only the US Dollar, Eurozone Euro, China Renminbi, Japan Yen and India Rupee, with a total value in circulation reaching \$ 213B (figure 7).

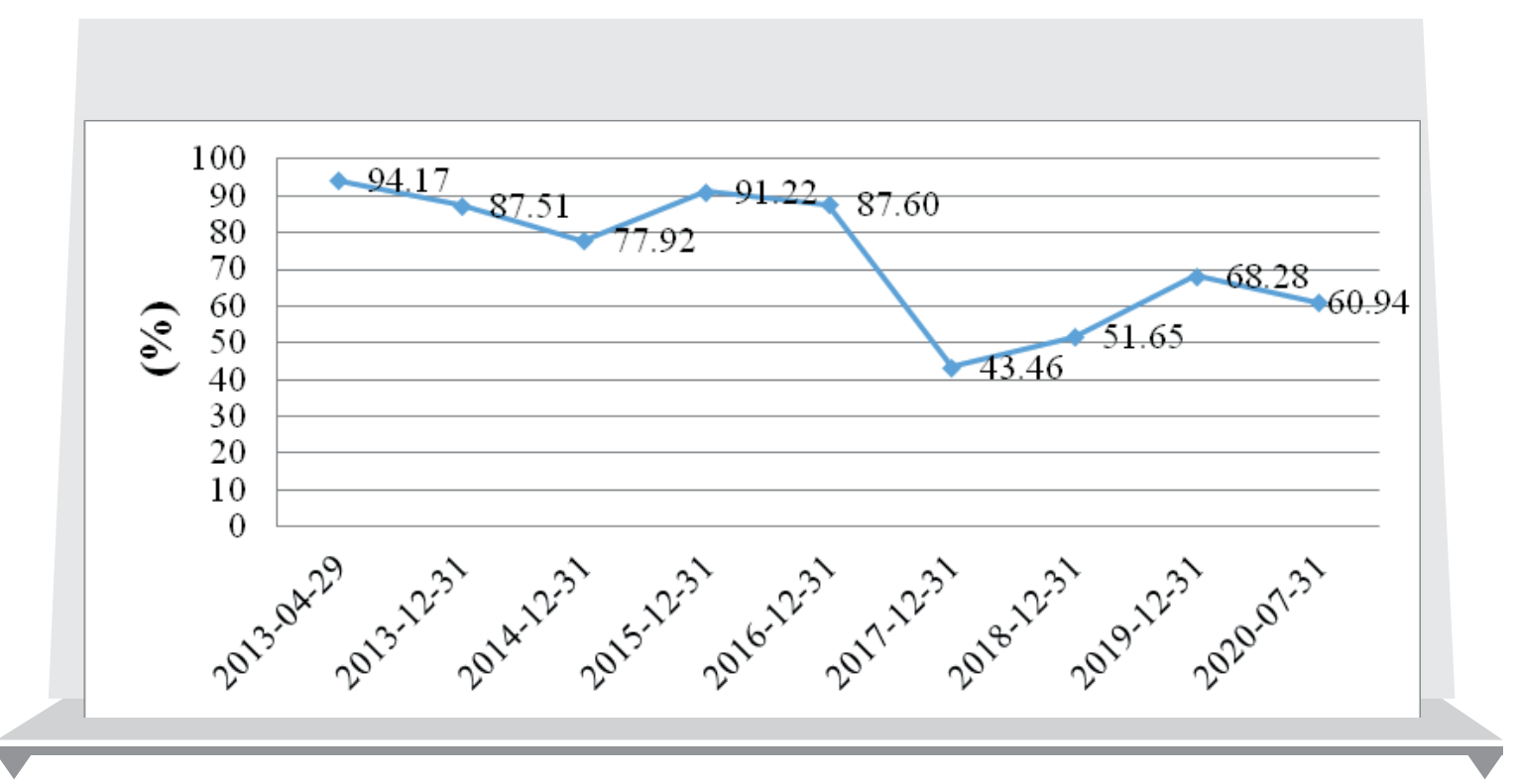

Figure 7. The ratio of market capitalization of Bitcoin to the total market capitalization of cryptocurrencies (\%)

Source: coinmarketcap (1/10/2020) 
The top fiat currencies used to trade virtual currencies are JPY (Japanese Yen) $(48 \%)$, USD (36\%), and EUR (14\%). The amount of virtual currency traded by markets is also the same trend when Japan, the US, and Europe are recorded as the most-traded cryptocurrency exchanges. The number of people using virtual wallets has increased dramatically. In the first quarter of 2015, there were just over 3 million users. But by the first quarter of 2018, this number has increased by about 8 times, which reached nearly 24 million users (HT Tam and NTK Phuong 2018).

Virtual money can now be exchanged for real money or used to buy goods and services. There have already been many companies that accept Bitcoin as a means of payment around the world. According to HT Tam and NTK Phuong (2018), the number of Bitcoin ATMs in April 2018 was 2,791 ATMs. They were located in 68 countries, mainly in the United States with more than 2,200 ATMs, following by Europe and Japan. As of July 28, 2020, according to website coinatmradar, there were 8,834 Bitcoin ATMs globally (figure 8).

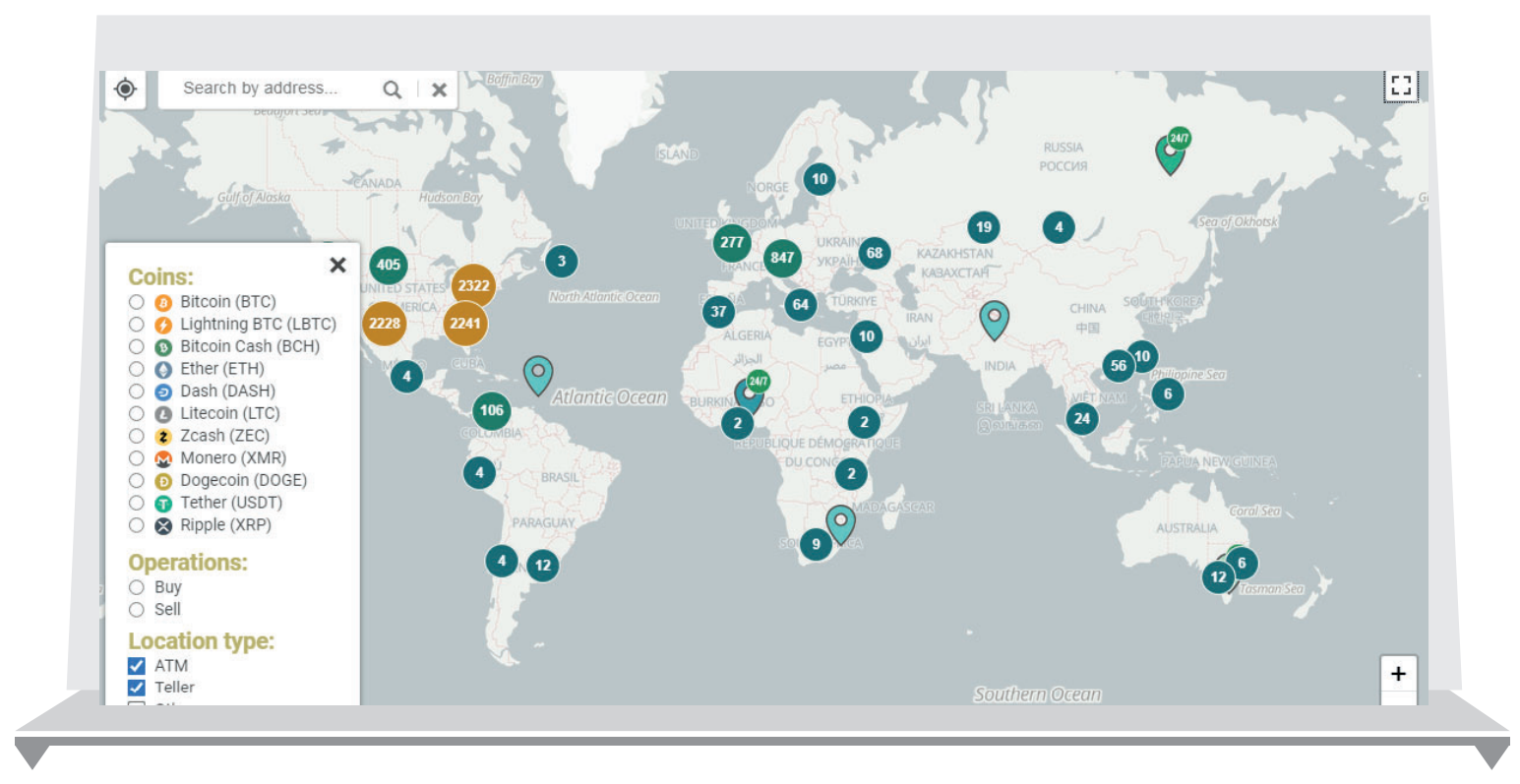

Figure 8. Number and location of Crypto ATMs in the world

Source: coinatmradar $(1 / 10 / 2020)$

\subsection{Current situation of using Bitcoin in Vietnam}

Although there have still been some reasons making Bitcoin not to become a real currency, in Vietnam that is similar to some countries in the world, there are

Current situation of Bitcoin management and use: perspectives from the world and recommendations for vietnam 
some stores accepting Bitcoin as a means of payment (T Xuan, 2018) Some global businesses have also allowed customers to pay by Bitcoin for their services, such as BitRefill's mobile recharge service, airline tickets service, hotel reservations and car rentals at Expedia, online purchase at OverStock, OpenBazaar or Dark Net Markets, gift cards at Gyft, domain names purchase and host services at NameCheap, VPN at BitVPN, fashion service at ASOS and a number of other small services at Fiverr...(NB Huyen, 2018). However, because "virtual money", in general, and Bitcoin, Litecoin, in particular, are not a currency and not a legal means of payment in accordance with Vietnam law (Official Letter 5747/ NHNN-PC (2017)), after the authority announced to tighten the inspection and supervision of virtual currency transactions, these stores stopped the payment by Bitcoin. Instead, they just announced to attract the public's attention.

The number of automatic data processing machines dedicated to mining cryptocurrencies that are imported to Vietnam in recent years also increased quite high. According to information from the General Department of Customs, from 2017 up to now, there have been 15,600 virtual currency miners being imported into Vietnam, while representatives of Ho Chi Minh City Customs Department said that from the beginning of 2018 until now, they made the procedure for 3,664 data processing machines (T Xuan, 2018). However, like Bitcoin payment, Bitcoin mining is not recognized and encouraged in Vietnam. According to Official Dispatch No. 5484/VPCP-KTTH dated June 9, 2018, the Government assigned the Ministry of Industry and Trade to assume the prime responsibility, and coordinate with the Ministry of Finance and concerned agencies in studying and considering the suspending import of data processing machines automatically exploiting virtual money according to its competence and regulations.

According to NB Huyen (2018), The State Bank of Vietnam granted licenses for 9 non-bank organizations providing e-wallet services (a form of virtual money), including MobiVi, VietUnion, VNPay, VinaPay, Smartlink, M_Service, VNPT-EP etc. According to the State Bank of Vietnam, there were approximately 1.84 million electronic wallet users with a total trading volume of $\$ 1.1$ billion at the end of 2013. But by 2016 this figure has grown to three million wallet users. Total number of wallet users is expected to cross the 10 million user mark by 2020.

On the other hand, although there is no detailed legal framework of virtual currency in Vietnam, investment activities, transactions, and fundraising capital in virtual currency in general, and Bitcoin, in particular, have been taking place strongly. Instead of official and public data to evaluate the level of the interest 
of Vietnamese users of virtual currencies, the search volume for the keyword "Bitcoin" or the number of visits to the top websites of virtual currency can be seen as a reference. For example, in 2017, the number of searches for the keyword "Bitcoin" from Vietnam ranked 41 in the most interest list of 63 markets. Japan, South Korea and Vietnam together accounted for 80 percent of bitcoin trading activity globally at the end of November 2017. In addition, in terms of search and access, for the ICO virtual currency investment page, the Vietnamese people also ranked 1st; for Bitconnect, Vietnam ranks 4th; and for other emerging sites like Hextracoin, Regalcoin, Ucoincash, etc, the country is also the leading (NB Huyen, 2018). Meanwhile, according to T Xuan (2018), the number of Vietnam's visitors to some Bitcoin exchanges or the world's virtual currency website such as Bittrex, Poloniex, or Coinmarketcap, always maintains in the top 5 with the United States, Russia, Japan.

Another activity related to virtual money is mobilizing virtual money. Typically, Sky Mining Virtual Currency Investment Company, established in 2017, called on investors to contribute capital with many different amounts of money, from 500 USD to thousands with an investor's return up to 300\% (for a period of 12 - 15 months). After the first time to pay interest on time, since June 2018, the Company delayed and did not pay interest as committed and so far, the investor has not received any money. Sky Company Mining also did not make an official announcement about the absence of the Board of Directors. Sky Company Mining also did not make an official announcement about the absence of the Board of Directors. Consequently, about 11,000 investors investing into this company were lost (LV Nam 2019).

\section{Conclusion and Suggestions}

Vietnam as well as most other countries do not consider virtual currency as the legal currency and legal means of payment in their territories. However, in order to adapt the general trend of the era of technology 4.0, proactively integrate as well as restrict, eventually eliminate fraudulent acts, appropriation of assets of organizations and individuals relating to virtual currency and Bitcoin, the article proposes some recommendation as follows:

Improving the legal framework for virtual currencies and Bitcoin as well. In particular: on August 27, 2018, the Prime Minister issued Decision No. 1255/ QD-TTG on Approving the Scheme of Completion of the Legal Framework on Management of Virtual Assets, Digital Currencies, and Virtual Currencies. According to this scheme, the building of a legal framework on virtual currencies

Current situation of Bitcoin management and use: perspectives from the world and recommendations for vietnam 
will contribute to protecting the legitimate rights and interests of domestic and foreign investors in Vietnam; effectively limit, prevent and control risks and abuse; concretize property rights regulated in the Civil Code 2015 in the field of virtual assets, electronic currency and virtual currency. However, until now, no particular regulations have been issued. Therefore, in order to ensure in issuing, circulating, and investing cryptocurrencies do not jeopardize money policy, the national currency, and the economic governance, Vietnam should recognize virtual currency as well as Bitcoin as a special type of asset, allowing them to be circulated under specific regulations. However, it is noticeable that the virtual currency should be recognized as a real currency.

Policies aiming to improve information technology infrastructure, build and improve the capacity of the finance, encryption, and security experts should continue to be issued.

Strengthening propagandas to help to improve people's awareness and understanding of Bitcoin as well as other virtual currencies. Although, in fact, the Ministry of Public Security has warned people not to invest, hold, and perform transactions related to virtual money, many people ignore these warnings. Therefore, the propaganda through official information channels such as television, newspaper, online newspapers, social networks, is necessary to help people understand the risks and have cautioned vigilance with virtual currency investment and trading, preventing the negative effects of virtual currency.

Violations related to virtual money must be fully and strictly handled. Although there have been sanctions for violations related to virtual money from administrative sanctions to criminal penalties, many people have lost money by investing in virtual currency projects. Therefore, Vietnam needs to provide authoritative guidance on the application of sanctions to virtual or digital currencies. Moreover, these sanctions must be broad enough to include any entities operating in the virtual/digital currency space.

Not only we propose policy implications for Bitcoin platform in emerging markets in the above session, One of different points of this study from other previous studies is that, in below session, we identify what are proper conditions to develop BItcoin platform in emerging markets:

Last but not least, conditions to develop Bitcoin platform in Vietnam and other emerging markets including:

1. Blockchain technology: maintaining safe technology with high security, risk management solutions need to be attached with wallets and accounts, more than $99 \%$ of cases out of hackers' intervention. 
2. Bitcoin is another kind of e-currency and needs to be ensured by a suitable amount of goods or services, otherwise, it will cause inflation happening. Goods or services can be any kind of form such as physical goods or products, real estates, services, etc...that can create value-added for society.

Finally, the development of new knowledge on the topic is that: Not only we need to establish legal framework to control Bitcoin, but also we need to perform risk management measurements and test blockchain before deciding implementation of Bitcoin in emerging markets. And this research has limitation: we need to expand more researches in Asia, China, India and emerging markets.

\section{Summary}

Current Situation Of Bitcoin Management and Use: Perspectives From The World And Recommendations For Vietnam

The research aimed to evaluate suitability of Bitcoin and its platform in emerging markets such as Vietnam. We used qualitative analysis combined with data collection method published, statistics, analysis, synthesis, comparison, to generate qualitative comments and discussion; evaluate results, the article analyzed and evaluated the impacts of Bitcoin and virtual currency on society of Vietnam, both positive and negative sides. It was found that virtual currency not accepted in Vietnam as means of payment yet, while many nations in the world accept it. We need to complete the legal framework for virtual currencies in general, Bitcoin in particular. The State should continue to have policies to improve information technology infrastructure, build and improve the capacity of the contingent of financial experts, encryption, and security experts and give warning risks in virtual currency transactions. The scientific value of paper is using experiences from previous studies in other countries to generate recommendations for conditions of Bitcoin development in merging markets. Last but not least, the research was limited to the case of Vietnam; hence, we can expand research to other Asian countries or other emerging markets.

Keywords: Bitcoin, virtual currency, cryptocurrencies, Vietnam.

JEL

Classification: E42, E5, E51 


\section{References}

Bajpai,P.(2020).Liquidity ofBitcoin, availableat:https:/ / www.investopedia. com/articles/ investing/112914/liquidity-bitcoins.asp\#: :text=The $\% 20$ concept $\% 20$ of $\%$ 20liquidity $\% 20$ has,influence $\%$ 20the $\% 20$ price $\% 20$ of $\% 20$ Bitcoin.\&text $=$ Liquidity $\%$ 20thus $\%$ 20means $\% 20$ that $\%$ 20there,item $\% 20$ is \% 20bought $\% 20$ and $\% 20$ sold.

Bohme, R., Christin, N., Elderman, B., \& Moore, T. (2015). Bitcoin: Economics, Technology, and Governance, The Journal of Economic Perspectives, 29(2).

fiahub - a, what is Bitcoin? Overview of the first cryptocurrency, available at: https://www.fiahub.com/blog/bitcoin-la-gi-tong-quan-ve-dong-tiendien-tu-dau-tien/(dated on 1/10/2020).

fiahub - b, Legal on virtual money in Vietnam 2020, available at: https:/ / www.fiahub.com/blog/phap-ly-ve-tien-ao-tai-viet-nam-2020/(dated on $1 / 10 / 2020)$.

fiahub - c, What is a crypto wallet? Cryptocurrency Wallet from A - Z TM, available at: https://www.fiahub.com/blog/vi-tien-dien-tu-la-gicryptocurrency-wallet-tu-a-z/(dated on 1/10/2020).

Franco, P. (2015). Understading Bitcoin, Cryptography, Engineering and Economics, Wiley Finance Series, 1st Edition, United Kingdom.

Gerba, E., Rubio, M. (2019). Virtual Money: How Much do Cryptocurrencies Alter the Fundamental Functions of Money?, pp. 32-60, Policy Department A - Economic and Monetary Affairs Committee (ECON), European Parliament, URL: https://www.ey.com/Publication/vwLUAssets/eythe-future-of-money/\$FILE/ ey-the-future-of-money.pdf.

Government of Vietnam (2016). Decree Amending and Supplementing a Number of Articles of the Government's Decree No. 101/2012/ND-CP dated November 22, 2012 on Non-Cash Payment, No. 80/2016/ND -CP, issued on July 1, 2016.

Government of Vietnam (2016). Decree on sanctioning administrative violations in the monetary and banking sector, No. 96/2014/ND-CP, issued on 17 October 2014.

https:// coinatmradar.com/(dated on 1/10/2020).

https:/ / coinmarketcap.com/(dated on 1/10/2020).

https://howmuch.net/articles/how-much-currencies-are-worth(dated on $1 / 10 / 2020)$.

Huyen, N.B. (2018). Bitcoin and its problems, Online Finance Magazine, available at: http://tapchitaichinh.vn/nghien-cuu--trao-doi/trao-doibinh-luan/ bitcoin-and-with-to-dat-139844.html.

Mizerka, J., Szajek, A.S., \& MIzerka, P. (2020). The role of Bitcoin on developed and emerging markets - on the basis of a Bitcoin users graph analysis, Finance Research Letters, 35. https://doi.org/10.1016/j. frl.2020.101489. 
Nam, L.V. (2019). Virtual money and the issue of building a legal framework for virtual money management in Vietnam, Online Finance Magazine, accessible at: http://tapchitaichinh.vn/ngan-hang/tien-aoand-to-use-frame-of-the-place-for-money-place-306097.html.

National Assembly of Vietnam 2010, Law on State Bank of Vietnam, No. 46/2010/QH12, dated June 16, 2010.

Nghia, L.T.T., Tung, N.T. (2018). Virtual Currency and Monetary Policy Challenges, Online Finance Magazine, available at: http:/ / tapchitaichinh.vn/ kinh-te-vi-mo/tien-ao-va-thach-washing-with-money-book-money-139856. html.

Oust, A., Nordstrom, F.B.G., Krogstad, E.A., Khazal, A., Kjaerland, F. (2018). An Analysis of Bitcoin's Price Dynamics, Journal of Risk and Financial Management, 11(63).

Pavel, C. et al (2016). The economics of BitCoin price formation, Applied Economics, vol. 48, no. 19, pp. 1799-1815.

Peters et al (2015), Trends in cryptocurrencies and blockchain technologies: a monetary theory and regulation perspective, The Journal of Financial Perspectives: FinTech, Vol. 3 - No 3, pp. 1-46.

Saiedi, E. et al (2020). Global drivers of cryptocurrency infrastructure adoption, Small Business Economics, URL: https://link.springer.com/content/ pdf/10.1007/s11187-019-00309-8.pdf.

Standing Committee of the National Assembly (2005). Ordinance on Foreign Exchange, No. 28/2005/PL-UBTVQH11, issued on December 13, 2005.

State Bank of Vietnam (2017). Official Letter Responding to Mr. Vu Thai Ha's Petition on the Design of Bitcoin, Litecoin and Virtual Currency Computer Centers, No. 5747/NHNN-PC, dated July 21, 2017.

Tam, H.T. and Phuong, N.T.K. (2018). Virtual currency and the situation of virtual money management in some countries around the world, Online Industry and Trade Magazine, available at: http:/ / tapchicongthuong.vn/bai-viet/ tien-ao-va -the-place-of-the-place-in-a-country-in-the-world-53772.htm. Vietnam National Assembly 2015, Civil Code, No. 91/2015/QH13, dated 24 November 2015.

Vietnam National Assembly 2015, Penal Code, No. 100/2015 /QH13, dated 27 November 2015.

Vietnam National Assembly 2017, Law Amending and Supplementing a Number of Articles of the Penal Code No. 100/2015/QH13, No. 12/2017/QH14, issued on June 20, 2017.

Weber, B. (2016). Bitcoin and the legitimacy crisis of money, Cambridge Journal of Economics, vol. 40, pp. 17-41.

Wikipedia, Bitcoin, available at: https://en.wikipedia.org/wiki/Bitcoin: (dated on 1/10/2020).

Current situation of Bitcoin management and use: perspectives from the world and recommendations for vietnam 
Xuan, T. (2018). Vietnam is Asia's leading virtual money trading market, accessible at: https://thanhnien.vn/tai-chinh-kinh-doanh/viet-nam-lathi-truong-giao-dich -tien-pond-top-head-after-a-977908.html.

Yen, B. (2018). Strengthen management measures to prevent negative effects of cryptocurrencies, available at: http://quochoi.vn/UserControls/ Publishing/News/BinhLuan/pFormPrint.aspx?UrlListProcess=/ content/tintuc / Lists / News \& ItemID = 36553 (dated on 1/10/2020). 